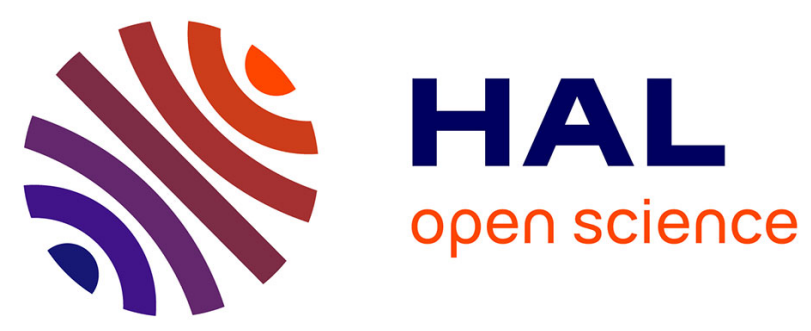

\title{
Beneficial effects of a N-terminally modified GIP agonist on tissue-level bone material properties.
}

Guillaume Mabilleau, Aleksandra Mieczkowska, Nigel Irwin, Yannick Simon, Maurice Audran, Peter-R. Flatt, Daniel Chappard

\section{To cite this version:}

Guillaume Mabilleau, Aleksandra Mieczkowska, Nigel Irwin, Yannick Simon, Maurice Audran, et al.. Beneficial effects of a N-terminally modified GIP agonist on tissue-level bone material properties.. BONE, 2014, 63, pp.61-8. 10.1016/j.bone.2014.02.013 . hal-03265959

\section{HAL Id: hal-03265959 \\ https://univ-angers.hal.science/hal-03265959}

Submitted on 21 Jun 2021

HAL is a multi-disciplinary open access archive for the deposit and dissemination of scientific research documents, whether they are published or not. The documents may come from teaching and research institutions in France or abroad, or from public or private research centers.
L'archive ouverte pluridisciplinaire HAL, est destinée au dépôt et à la diffusion de documents scientifiques de niveau recherche, publiés ou non, émanant des établissements d'enseignement et de recherche français ou étrangers, des laboratoires publics ou privés. 


\title{
Beneficial effects of a N-terminally modified GIP agonist on tissue-level bone material properties
}

\author{
Guillaume Mabilleau $^{\mathrm{a}, \mathrm{b}, *}$, Aleksandra Mieczkowska a , Nigel Irwin ${ }^{\mathrm{c}}$, Yannick Simon ${ }^{\mathrm{a}, \mathrm{d}}$, Maurice Audran ${ }^{\mathrm{a}, \mathrm{d}}$, \\ Peter R. Flatt ${ }^{c}$, Daniel Chappard ${ }^{\mathrm{a}, \mathrm{b}}$ \\ a LUNAM Université, GEROM-LHEA, Institut de Biologie en Santé, Angers, France \\ b LUNAM Université, SCIAM, Institut de Biologie en Santé, Angers, France \\ c School of Biomedical Sciences, University of Ulster, Coleraine, U K \\ ' Service de Rhumatologie, CHU d'Angers, Angers, France
}

\section{A R T I C L E I N F O}

\section{Article history:}

Received 23 December 2013

Revised 19 February 2014

Accepted 21 February 2014

Available online 1 March 2014

Edited by David Fyhrie

\section{Keywords:}

N-AcGIP

Bone material properties

qBEI

Nanoindentation

Collagen maturity

\begin{abstract}
A B S T R A C T
Bone remodeling is under complex regulation from nervous, hormonal and local signals, including gut hormones. Among the gut hormones, a role for the glucose-dependent insulinotropic polypeptide (GIP) has been suggested. However, the rapid degradation of GIP in the bloodstream by the ubiquitous enzyme dipeptidyl peptidase- 4 (DPP-4) precludes therapeutic use. To circumvent this problem, a series of N-terminally modified GIP agonists have been developed, with N-AcGIP being the most promising. The aims of the present study were to investigate the effects of N-AcGIP on bone at the micro-level using trabecular and cortical microstructural morphology, and at the tissue-level in rats. Copenhagen rats were randomly assigned into control or N-AcGIP-treated groups and received daily injection for 4 weeks. Bone microstructural morphology was assessed by microCT and dynamic histomorphometry and tissue-level properties by nanoindentation, qBEI and infra-red microscopy. Four week treatment with N-AcGIP did not alter trabecular or cortical microstructural morphology. In addition, no significant modifications of mechanical response and properties at the tissue-level were observed in trabecular bone. However, significant augmentations in maximum load (12\%), hardness (14\%), indentation modulus (13\%) and dissipated energy (16\%) were demonstrated in cortical bone. These beneficial modifications of mechanical properties at the tissue-level were associated with increased mineralization (22\%) and collagen maturity (13\%) of the bone matrix. Taken together, the results support a beneficial role of GIP, and particularly stable analogs such as N-AcGIP, on tissue material properties of bone.
\end{abstract}

(c) 2014 Elsevier Inc. All rights reserved.

\section{Introduction}

Glucose-dependent insulinotropic polypeptide (GIP) is an important gastro-intestinal hormone synthesized and secreted into the bloodstream by the duodenal endocrine $\mathrm{K}$ cells after ingestion of a mixed meal $[1,2]$. To induce a biological response, it binds to a specific receptor, the glucose-dependent insulinotropic polypeptide receptor (GIPR) [3]. Despite a wide distribution of the GIPR in the body, the most recognized action of GIP is to potentiate glucose-stimulated insulin secretion from pancreatic $\beta$-cells [4]. Recently, the presence of a functional GIPR has been evidenced at the surface of osteoblasts and osteoclasts [5-7]. Further to this, GIP stimulates the synthesis of collagen type I and TGF- $\beta$ by osteoblasts in vitro $[5,8]$ and directly reduces osteoclast activity in mature murine osteoclast cultures [7]. Recently, we also reported that mice lacking a functional GIPR present with severe alterations of bone microstructural morphology and tissue properties leading to

\footnotetext{
* Corresponding author at: GEROM-LHEA UPRES EA 4658, Institut de Biologie en Santé, Université d'Angers, 4 rue Larrey, 49933 Angers Cedex 09, France. Fax: + 33244688350. E-mail address: guillaume.mabilleau@univ-angers.fr (G. Mabilleau).
}

decreased bone strength $[9,10]$. Taken together, these data suggest a beneficial role of the GIPR signaling pathway in bone.

However, following secretion into the bloodstream, GIP is rapidly inactivated through cleavage of the first two N-terminal amino acids by the endopeptidase dipeptidyl peptidase-4 (DPP-4), resulting in the formation of an inactive truncated metabolite [11]. The circulating half-life of native GIP is approximately 2 and $7 \mathrm{~min}$ in rodents and healthy subjects, respectively $[12,13]$. The susceptibility to DPP-4 cleavage precludes the use of native GIP as a therapeutic option. Previously, we have developed a series of DPP-4-resistant GIP analogs through modification of the N-terminal region of native GIP [14-17]. Acetylation of $\mathrm{Tyr}^{1}$ in GIP (N-AcGIP) generated an enzymatically stable and potent GIP analog with a circulating half-life greater than $24 \mathrm{~h}$ [15]. However, little is known about the potential effects of N-AcGIP on bone at the micro- and tissue-level, especially in relation to microstructural morphology and tissue properties.

Therefore, the aim of the present study was to conduct a comprehensive investigation of bone properties at the micro- and tissue-level in rats treated with N-AcGIP for a period of 4 weeks. Our results indicated that N-AcGIP did not profoundly modify bone microstructural 
morphology, but did dramatically increase tissue properties through increasing bone mineral density distribution and maturity of the collagen matrix.

\section{Material and methods}

\section{Synthesis, purification and characterization of N-AcGIP}

$\mathrm{N}$-AcGIP was sequentially synthesized using standard solid-phase Fmoc peptide chemistry as described previously, with an acetyl adduct incorporated at the N-terminal $\operatorname{Tyr}^{1}$ [15]. N-AcGIP was judged pure by reversed-phase HPLC and subsequently characterized using matrix assisted laser desorption ionization-time of flight mass spectrometry (MALDI-Tof MS), as described previously [15].

\section{Cell culture}

MC3T3-E1 cells were purchased from American type culture collection (ATCC, Teddington, UK) and used as a source of osteoblasts. Cells were grown and expanded at a ratio 1:4 in propagation medium containing $\alpha$ MEM supplemented with 5\% FBS, 5\% bovine calf serum, $100 \mathrm{U} / \mathrm{mL}$ penicillin, and $100 \mu \mathrm{g} / \mathrm{mL}$ streptomycin (Lonza, Verviers, Belgium) in a humidified atmosphere enriched with $5 \% \mathrm{CO}_{2}$ at $37{ }^{\circ} \mathrm{C}$. For differentiation studies, cells were detached with trypsin-EDTA and plated at a density of $1.5 \times 10^{4}$ cells $/ \mathrm{cm}^{2}$ and grown to confluence in propagation medium. At confluence, the propagation medium was replaced by the differentiation medium containing $\alpha$ MEM supplemented with $5 \%$ FBS, $5 \%$ bovine calf serum, $100 \mathrm{U} / \mathrm{mL}$ penicillin, $100 \mu \mathrm{g} / \mathrm{mL}$ streptomycin, and $50 \mu \mathrm{g} / \mathrm{mL}$ ascorbic acid $\pm 50 \mathrm{pM} \mathrm{N}$-AcGIP. This day was considered as day 1 . The differentiation medium was replenished every 48 h until day 12 . At day 12 , culture supernatants were harvested, spun at $3000 \mathrm{rpm}$ for $15 \mathrm{~min}$, aliquoted and frozen at $-80^{\circ} \mathrm{C}$ until use. Collagen maturity was determined spectroscopically as reported elsewhere [18]. Briefly, the remaining matrix was rinsed in phosphate buffer saline followed by absolute ethanol. The matrix was then scraped off the culture plate, transferred onto $\mathrm{BaF}_{2}$ windows, and air-dried and collagen maturity was determined spectroscopically as described below.

\section{Alkaline phosphatase (AlkP) activity}

AlkP activity was determined in the culture supernatants using 4-methyl umbelliferyl phosphate, as previously reported [19]. Briefly, in the presence of AlkP, 4-MUP is converted into the fluorescent 4methyl umbelliferone (4-MU) [20,21]. Fluorescence was read using a M2 microplate reader (Molecular Devices, St Gregoire, France) with excitation and emission wavelength set to 360 and $450 \mathrm{~nm}$, respectively. Protein concentration was also determined using a BCA protein assay kit (Pierce Biotechnology, Rockford, IL).

\section{Mineralization assay}

MC3T3 cells were plated at a density of $1.5 \times 10^{4}$ cells $/ \mathrm{cm}^{2}$ and grown to confluence in propagation medium. At confluence, the propagation medium was replaced by the mineralization medium containing $\alpha$ MEM supplemented with $5 \% \mathrm{FBS}, 5 \%$ bovine calf serum, $100 \mathrm{U} / \mathrm{mL}$ penicillin, $100 \mu \mathrm{g} / \mathrm{mL}$ streptomycin, $50 \mu \mathrm{g} / \mathrm{ml}$ ascorbic acid, and $2.5 \mathrm{mM} \beta$ glycerophosphate $\pm 50 \mathrm{pM} \mathrm{N}$-AcGIP. The mineralization medium was replenished every two days until day 15 . At the end of the incubation period, cells were fixed with $3.7 \%(\mathrm{w} / \mathrm{v})$ formaldehyde in PBS for $10 \mathrm{~min}$, rinsed with PBS and stained with $1 \%(\mathrm{w} / \mathrm{v})$ Alizarin red S for $5 \mathrm{~min}$. The plates were then rinsed three times with $50 \%$ ethanol and left to air dry. The extent of mineralization was assessed by image analysis with ImageJ.
Animals

Twelve Copenhagen rats (5 month old; Charles River, L'Arbresle, France) were used in this study. Our previous studies suggested that upregulated GIPR signaling could potentially decrease trabecular bone volume [9]. As such, we used the Copenhagen rats that present with high trabecular and normal cortical components [22]. Animals were maintained on a $12 \mathrm{~h}: 12 \mathrm{~h}$ light-dark cycle in a temperature-controlled room $\left(21.5 \pm 1{ }^{\circ} \mathrm{C}\right)$ and received standard laboratory food (UAR, Villemoison-sur-Orge, France) and water ad libitum. All procedures were conducted in accordance with the official regulation of the French Ministry of Agriculture and were approved by the Animal Care and Use committee of the University of Angers. Animals were randomly allocated at day 0 into two groups of six animals receiving an intraperitoneal (IP) injection of either $25 \mathrm{nmol} / \mathrm{kg}$ body weight/day N-AcGIP or saline vehicle $(0.9 \%(\mathrm{w} / \mathrm{v}) \mathrm{NaCl})$. Intraperitoneal injections were carried out for 4 weeks, 5 days a week. This dose of N-AcGIP has been chosen based on previous animal studies $[15,23,24]$. Animals were labeled with calcein ( $10 \mathrm{mg} / \mathrm{kg}$ body weight) according to the following schedule: 2 days with calcein, 10 days without calcein and 2 days with calcein. The last injection of calcein was made 3 days prior to sacrifice. Blood samples $(\sim 3 \mathrm{ml})$ were collected from the left ventricle by intracardiac aspiration at sacrifice. In addition, at the end of the study bones were rapidly harvested, soft tissue removed and either formalin or ethanol fixed, as reported in Fig. 1.

\section{Body mass, composition and food intake measurements}

Food intake was determined daily using a precision balance (Adventurer $^{\mathrm{TM}}$ Pro, Ohaus, Nanikon, Switzerland) and animals were weighed on a weekly basis. Lean and fat percentage were measured by dual energy X-ray absorptiometry (DEXA) using a Hologic Discovery A system (Hologic Inc., Bedford, MA) endowed with small animal software at necropsy.

\section{Microcomputed tomography}

The tibia was used to investigate trabecular and cortical bone microstructural morphology by microCT analysis with a Skyscan 1172 microtomograph (Bruker, Kontich, Belgium) equipped with an X-ray tube working at $69 \mathrm{kV} / 100 \mu \mathrm{A}$. The pixel size was fixed at $8.3 \mu \mathrm{m}$, the rotation step at $0.25^{\circ}$ and exposure was performed with a $0.5-\mathrm{mm}$ aluminum filter. Bone mass and morphometry parameters were calculated with the CTan software (release 1.11.4.2, Bruker). The trabecular parameters were assessed at the volume of interest (VOI), located $1 \mathrm{~mm}$ below the growth plate and spanning $2.5 \mathrm{~mm}$ in height (302 sections). Trabecular bone volume (BV/TV, in \%), trabecular thickness (Tb.Th, in $\mu \mathrm{m})$, trabecular number (Tb.N, in $1 / \mathrm{mm}$ ), trabecular separation ( $\mathrm{Tb} . \mathrm{Sp}$, in $\mu \mathrm{m}$ ), trabecular pattern factor (Tb.Pf) and structure model index (SMI) were measured according to guidelines and nomenclature proposed by the American Society for Bone and Mineral Research [25]. Cortical parameters were determined at the midshaft tibia with a lab-made routine using ImageJ. Bone diameter (B.Dm, in mm), marrow diameter (Ma.Dm, in $\mathrm{mm}$ ), cortical thickness (Ct.Th, in $\mu \mathrm{m}$ ) and cross-sectional moment of inertia (CSMI, in $\mathrm{mm}^{4}$ ) were measured according to guidelines and nomenclature on bone histomorphometry proposed by the American Society for Bone and Mineral Research [26].

\section{Bone histomorphometry}

Undecalcified left tibias were embedded in poly (methylmethacrylate) (pMMA) at $4{ }^{\circ} \mathrm{C}$ to preserve enzyme activities. Sections (7- $\mu \mathrm{m}$ thickness) were cut on a heavy duty microtome equipped with a $50^{\circ}$ tungsten carbide knife. Trabecular analyses were performed on longitudinal sections at the proximal metaphysis. Cortical analyses were performed at the tibia midshaft on cross-sections. For each animal, four 


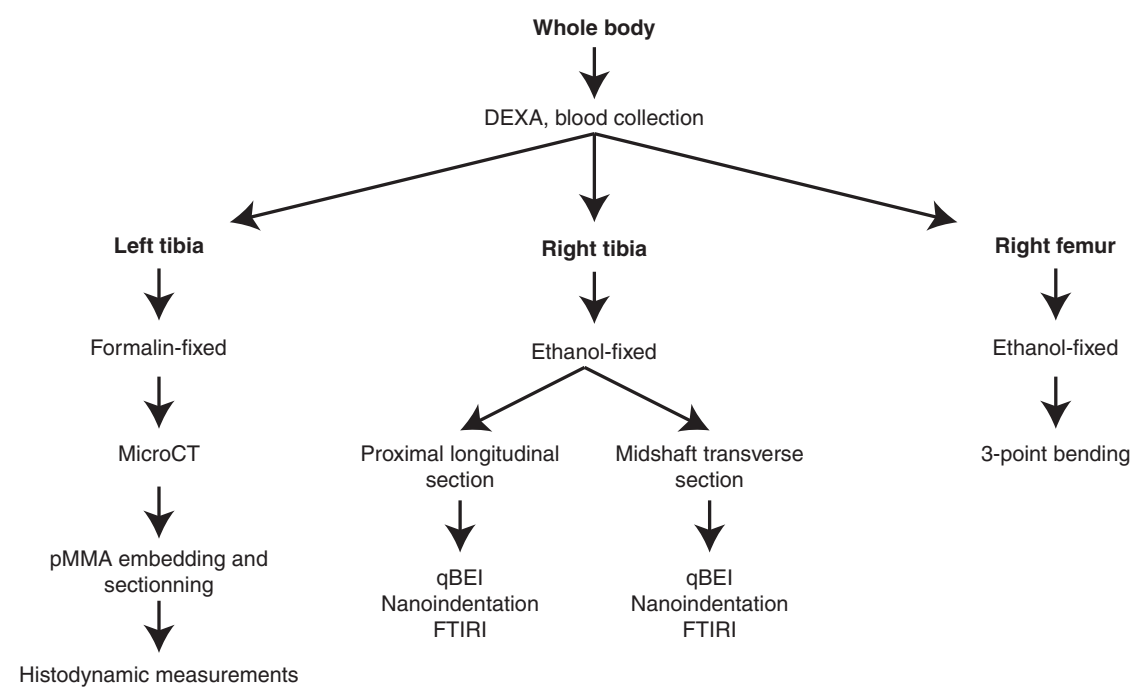

Fig. 1. Schematic representation of the experimental design.

nonserial sections ( $\sim 50 \mu \mathrm{m}$ apart) were left unstained for the measurement of calcein-based parameters (original magnification $\times 400$ ) and four sections were stained for the osteoclastic tartrate resistant acid phosphatase (TRAcP-original magnification of $\times 200$ ), as previously described [27]. Only TRAcP-positive multinucleated cells in contact with endosteal surface were counted as osteoclasts. Standard bone histomorphometrical nomenclatures, symbol and units were used as described in the report of the American Society for Bone and Mineral Research [26].

\section{Serum levels of bone markers}

Blood samples were collected in EDTA-treated tubes and immediately centrifuged at $3000 \mathrm{rpm}$ for $15 \mathrm{~min}$. Supernatants were used as serum samples, aliquoted and stored at $-80^{\circ} \mathrm{C}$ until further analysis. Serum levels of osteocalcin and C-terminal telopeptide of collagen type I ( $\mathrm{sCTx}$ ) were measured with the rat-MID osteocalcin EIA and RatLaps ELISA kits, respectively (Immunodiagnostic Systems Ltd, Boldon, UK), according to the manufacturer recommendations.

\section{Bone mechanical testing}

Three-point bending experiments were performed on the right femur. Before mechanical testing, femurs were rehydrated in saline for $24 \mathrm{~h}$ at room temperature. Three-point bending strength was measured with a constant span length of $20 \mathrm{~mm}$ on an Instron 5942 (Instron, Elancourt, France). The press head, as well as the two support points, were rounded to avoid shear load and cutting. Femurs were positioned horizontally with the anterior surface facing upward, centered on the support and the pressing force applied vertically to the midshaft of the bone. Each bone was tested with a loading speed of $2 \mathrm{~mm} \mathrm{~min}^{-1}$ until failure with a $500 \mathrm{~N}$ load cell. The load-displacement curve was acquired with the Bluehill 3 software (Instron) and converted into stress-strain curve. Material properties such as ultimate strength, ultimate strain and bending modulus were calculated according to previously published equations [28]. The work to fracture, corresponding to a measure of bone toughness was calculated according to Ritchie and al. [29].

\section{Quantitative backscattered electron imaging (qBEI)}

Quantitative backscattered electron imaging was employed to determine the bone mineral density distribution (BMDD) [30]. Tibias stored in $70 \%$ ethanol were cut in three portions (Fig. 1), the upper and mid portions were then dehydrated and embedded undecalcified in polymethylmethacrylate, as reported previously [31]. With a diamond saw (Accutom, Struers, France), the upper portion was cut longitudinally to expose trabecular bone while the mid portion was cut perpendicular to expose the cross-sectional section of the midshaft. PMMA blocks were polished to a 1- $\mu \mathrm{m}$ finish with diamond particles, carboncoated and observed with a scanning electron microscope (EVO LS10, Carl Zeiss Ltd, Nanterre, France) equipped with a five quadrant semiconductor backscattered electron detector. The microscope was operated at $20 \mathrm{keV}$ with a probe current of $250 \mathrm{pA}$ and a working distance of $15 \mathrm{~mm}$. The backscattered signal was calibrated using pure carbon $(Z$ $=6$, mean gray level $=25)$, pure aluminum $(Z=13$, mean gray level $=225)$ and pure silicon $(Z=14$, mean gray level $=253)$ standards (Micro-analysis Consultants Ltd, St Ives, UK). For these contrast/ brightness settings, the BSE gray level histogram was converted into weight percentage of calcium as described in Roschger et al. [30]. Changes in brightness and contrast due to instrument instabilities were checked by monitoring the current probe and imaging the reference material ( $\mathrm{C}, \mathrm{Al}$ and $\mathrm{Si}$ ) every $15 \mathrm{~min}$. The trabecular region of interest was located $1 \mathrm{~mm}$ below the growth plate on a height of $2.5 \mathrm{~mm}$. The cortical region of interest was represented by the tibia midshaft. ROIs were imaged at a $100 \times$ nominal magnification, corresponding to a pixel size of $1 \mu \mathrm{m}$ per pixel. The gray level distribution of each image was analyzed with a lab-made routine using Image as previously reported [32]. Three variables were obtained from the bone mineral density distribution: $\mathrm{Ca}_{\text {peak }}$ as the most frequently observed calcium concentration, $\mathrm{Ca}_{\text {mean }}$ as the average calcium concentration and $\mathrm{Ca}_{\text {width }}$ as the width of the histogram at half maximum of the peak.

\section{Nanoindentation}

Nanoindentation tests evaluated the mechanical properties of the bone matrix at the tissue-level. As nanoindentation assesses volume of material at a length scale less than that of individual microstructural features in bone, this technique avoids confounding factors such as microstructure and porosity that affect tissue properties at larger length scales. Tests were performed on the same sample used for qBEI measurements after rapid polishing. Tibias were rehydrated overnight in saline prior to nanoindentation testing as previously reported [32]. The same trabecular and cortical bone ROIs used for qBEI were assessed by nanoindentation. In trabecular regions, twenty-five indentations were positioned either in the center of several trabecula. In cortical regions, indentations were performed on the cut face of the cortical crosssection by drawing a line with twenty-five positions, extending from 
endosteal to periosteal surfaces. Indentations were made with a NHTTTX system (CSM, Peseux, Switzerland) equipped with a Berkowitch diamond probe. Indentations were performed up to a depth of $900 \mathrm{~nm}$ with a loading/unloading rate of $40 \mathrm{mN} / \mathrm{min}$. At maximum load, a holding period of $15 \mathrm{~s}$ was applied to avoid creeping of the bone material. Maximum load, indentation modulus, hardness and dissipated energy were determined according to Oliver and Pharr [33].

\section{Fourier transform infrared microscpectroscopy (FTIRM)}

Sections ( $4 \mu \mathrm{m}$ thickness) of pMMA blocks were cut dry on a heavy duty microtome equipped with tungsten carbide knives (Leica Polycut $\mathrm{S}$ ) and sandwiched between $\mathrm{BaF}_{2}$ optical windows. Spectral analysis were obtained on a Bruker Vertex 70 spectrometer (Bruker optics, Ettlingen, Germany) interfaced with a Bruker Hyperion 3000 infrared microscope equipped with a standard single element Mercury Cadmium Telluride (MCT) detector $\left(750-4000 \mathrm{~cm}^{-1}\right)$. Infrared spectra were recorded at a resolution of $4 \mathrm{~cm}^{-1}$, with an average of 32 scans in transmission mode. Background spectral images were collected under identical conditions from the same $\mathrm{BaF}_{2}$ windows at the beginning and end of each experiment to ensure instrument stability. For FTIR analysis, the same trabecular and cortical bone regions as reported above were assessed. As the samples had been calcein-labeled, measurements were made exclusively between the two labels (tissue age 5 - 15 days), to reflect N-AcGIP treatment period. Measurements were taken from 10 matrix of 6 spectra acquired on trabecular and cortical bones (same ROIs as above) and analyzed with the Opus Software (release 5.5, Bruker). The relative contribution of embedding polymethylmethacrylate (pMMA) and water vapor was corrected for each spectrum prior to baseline correction. The 6 spectra of each matrix were then averaged and the resulting spectrum was subjected to curve fitting using a commercial available software package (Grams/AI 8.0, Thermofisher scientific, Villebon sur Yvette, France). Every absorption band was characterized by its area using the Levenberg-Maquardt algorithm. The second derivative spectrum was used to determine the number and the position of the bands constituting every spectral interval. Position, height, width at half intensity and area were also obtained. Peaks corresponding to amide I (1585-1725 $\left.\mathrm{cm}^{-1}\right), v 2 \mathrm{CO}_{3}^{2-}$ region $\left(850-890 \mathrm{~cm}^{-1}\right)$ and $v 1 v 3$ phosphate $\left(900-1200 \mathrm{~cm}^{-1}\right)$ were considered for further analysis. The evaluated IR spectral parameters were (1) mineral-to-matrix ratio, calculated as the ratio of integrated areas of the $v 1 v 3$ phosphate (900-1200 $\left.\mathrm{cm}^{-1}\right)$ to the amide I (1585-1725 $\mathrm{cm}^{-1}$ ) bands [34], (2) carbonate-to-phosphate ratio, calculated as the ratio of integrated areas of the $v 2 \mathrm{CO}_{3}^{2-}$ region $\left(850-890 \mathrm{~cm}^{-1}\right)$ to the $v 1 v 3$ phosphate (900-1200 $\mathrm{cm}^{-1}$ ) bands [35] and (3) collagen maturity, determined as the relative ratio of pyridinium trivalent (Pyr, mature collagen) to dehydrodihydroxylysinonorleucine divalent (deH-DHLNL, new collagen) collagen cross-links using their respective subbands located at $1660 \mathrm{~cm}^{-1}$ and $1690 \mathrm{~cm}^{-1}$ of the Amide I peak [36].

\section{Statistical analysis}

Results were expressed as mean \pm standard error of the mean (SEM). Analysis of variance (ANOVA) with Levene's test of homogeneity was used to compare the differences between the groups using the Systat statistical software release 13.0 (Systat software Inc., San Jose, $\mathrm{CA}$ ). Differences at $\mathrm{p}<0.05$ were considered significant.

\section{Results}

Treatment with N-acGIP did not alter body mass composition or food intake

No adverse effects were observed following long term administration of N-AcGIP. As reported in Fig. 2, we did not observe significant differences in food intake ( $p=0.570)$, animal mass $(p=0.685)$, lean mass ( $p=0.659)$ or fat mass $(\mathrm{p}=0.785)$ between saline or N-AcGIPtreated animals during the time course of the study.

4-week treatment with N-AcGIP did not modify bone morphology at the micro-level despite higher cortical remodeling

Differences in morphology parameters of trabecular bone were investigated between saline- and N-AcGIP-treated rats (Table 1). Although BV/TV was reduced in N-AcGIP-treated animals compared to controls ( $37.4 \pm 1.2 \%$ vs. $39.1 \pm 1.1 \%$, respectively), this difference did not reach statistical significance $(\mathrm{p}=0.327)$. Tb.Th, Tb.N, Tb.Sp, Tb.Pf, SMI, Tb.MAR, BFR/BS and N.Oc/B.Pm were not significantly different between saline and N-AcGIP-treated animals (Table 1). No significant differences were observed between the two groups of animals in any of the cortical bone parameters (Table 2). On the other hand, calcein labeling was evident at the endosteal surface and Ct.MAR and N.Oc/Ec.Le were higher in N-AcGIP-treated animals (Table 2). We also assessed the circulating levels of total osteocalcin and sCTx (Fig. 3). We did not evidence any significant differences in the serum levels of these two biomarkers $(\mathrm{p}=0.532$ and $\mathrm{p}=0.456$ respectively).

4-week treatment with N-AcGIP increased tissue properties in cortical bone

Mechanical properties of bone tissue were investigated by threepoint bending and nanoindentation. In contrast to three-point bending, nanoindentation is not influenced by bone porosity, and reflects the mechanical response at the tissue-level. Bending stress, bending modulus and strain were increased in N-AcGIP-treated animals as compared to controls, but these differences did not reach statistical significance (Table 3). On the other hand, the work to fracture in N-AcGIP-treated animals was significantly ( $40 \%$; $p=0.025$ ) higher.

None of the studied parameters investigated by nanoindentation were significantly different between saline- and N-AcGIP-treated animals in trabecular bone (Table 4). On the other hand, in cortical bone, maximum load, hardness, indentation modulus and dissipated energy were significantly increased by $12 \%, 14 \%, 13 \%$ and $16 \%$, respectively, in $\mathrm{N}$-AcGIP-treated animals as compared with saline treated controls (Table 4).

4-week treatment with N-AcGIP increased bone mineral density distribution and collagen maturity in cortical bone

As reported in Table 5, none of the qBEI parameters in trabecular bone was significantly different in N-AcGIP-treated animals as compared with saline-treated animals. On the other hand, in cortical bone, $\mathrm{Ca}_{\text {peak }}$ and $\mathrm{Ca}_{\text {mean }}$ were both significantly elevated by $9 \%$ ( $\mathrm{p}=0.042$ and $\mathrm{p}=0.043$, respectively) in N-AcGIP-treated animals as compared with saline-treated animals. However, $\mathrm{Ca}_{\text {width }}$ was unchanged between the two groups of animals.

Furthermore, collagen maturity, mineral-to-matrix and carbonate-tophosphate ratios were not different in trabecular bone of saline- or N-AcGIP-treated animals (Fig. 4A). However, in cortical bone, collagen maturity and mineral-to-matrix ratios were significantly increased by $13 \%(p=0.045)$ and $22 \%(p=0.045)$, respectively, in N-AcGIP-treated animals as compared to saline controls (Fig. 4B).

$N$-AcGIP induced increased collagen maturity, AlkP activity and mineralization in vitro

In order to assess whether N-AcGIP could increase collagen maturity and AlkP activity in vitro, MC3T3 cells were treated for 12 days with 50 pM N-AcGIP. As represented Fig. 5, collagen maturity was significantly augmented by N-AcGIP $(57 \%$; $=0.038)$ as compared to control cultures. AlkP activity was also significantly higher in $\mathrm{N}$ AcGIP-treated cultures ( $p=0.037$ ). Furthermore, Alizarin red 
(A)

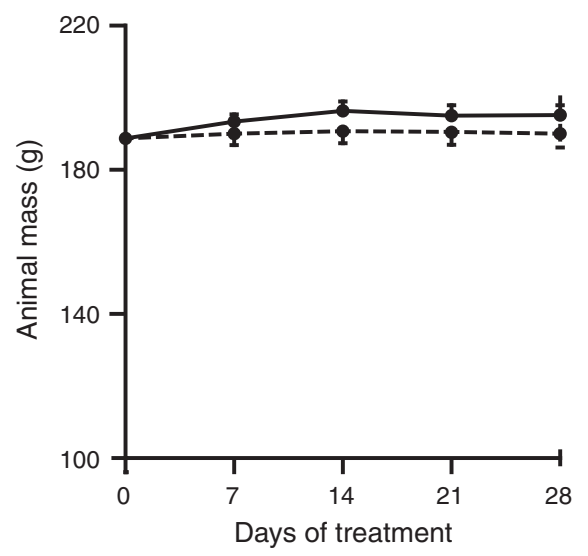

(C)

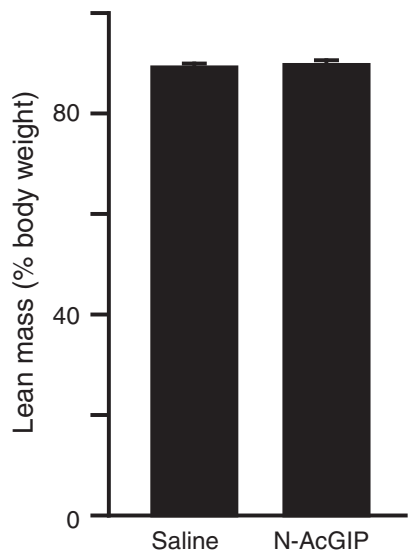

(B)

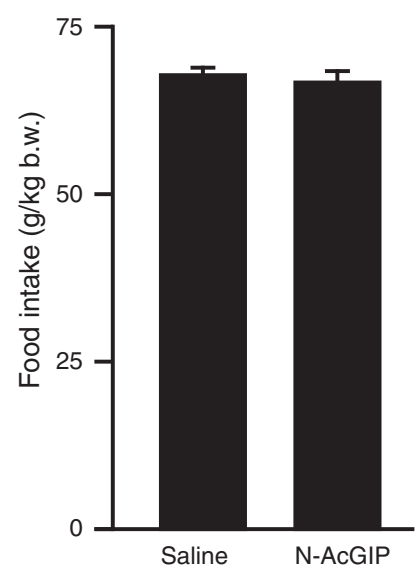

(D)

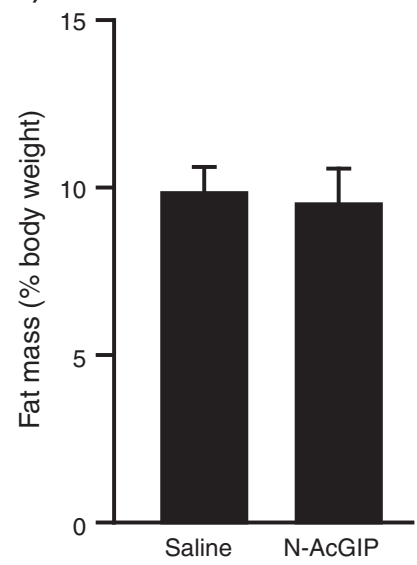

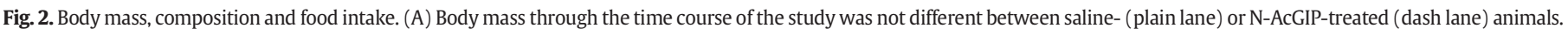
(B) Daily food intake, (C) lean mass and (D) fat mass were similar in saline- and N-AcGIP-treated animals.

staining of 15-day old cultures revealed larger mineralization in the presence of N-AcGIP $(p=0.001)$.

\section{Discussion}

Bone remodeling is a complex mechanism regulated by nervous, hormonal and local signals. Among all these signals, a role for gastrointestinal hormones such as GIP has been suggested. Previously, we reported that mice lacking a functional GIP receptor presented with dramatic alterations of trabecular and cortical bone microstructural morphology, and tissue-level material properties, leading to reduced bone strength $[9,10]$. In the present study, we have investigated the effects of 4 week treatment with a stable and potent GIP agonist, NAcGIP [15], on trabecular and cortical bone microstructural morphology and remodeling, as well as tissue properties.

Previously we highlighted that genetically-induced GIPR deficiency was associated with increased trabecular bone mass [9]. Therefore, in the present study we investigated the potential effect of N-AcGIP on trabecular bone morphology and bone cell parameters. Although BV/TV was lower in GIP analog treated animals as compared to controls, this did not reach statistical significance. None of the other parameters (Tb.Th, Tb.N, Tb.Sp, Tb.Pf, SMI, Tb.MAR, BFR/BS and N.Oc/B.Pm) were statistically different between groups. Furthermore, no noticeable
Table 1

Trabecular morphology parameters between saline- and N-AcGIP-treated animals.

\begin{tabular}{lccl}
\hline & Saline-treated animals & N-AcGIP-treated animals & p values \\
\hline BV/TV $(\%)$ & $39.1 \pm 1.1$ & $37.4 \pm 1.2$ & 0.327 \\
Tb.Th $(\mu \mathrm{m})$ & $112.4 \pm 1.5$ & $111.2 \pm 1.6$ & 0.580 \\
Tb.N $(1 / \mathrm{mm})$ & $3.5 \pm 0.2$ & $3.4 \pm 0.2$ & 0.322 \\
Tb.Sp $(\mu \mathrm{m})$ & $195.5 \pm 5.6$ & $202.8 \pm 7.1$ & 0.441 \\
Tb.Pf & $0.0024 \pm 0.0005$ & $0.0027 \pm 0.0004$ & 0.552 \\
SMI & $0.85 \pm 0.07$ & $0.90 \pm 0.06$ & 0.655 \\
Tb.MAR $(\mu \mathrm{m} /$ day $)$ & $2.8 \pm 0.2$ & $3.3 \pm 0.2$ & 0.394 \\
BFR/BS & $0.8 \pm 0.1$ & $1.0 \pm 0.2$ & 0.478 \\
$\quad\left(\mu \mathrm{m}^{3} / \mu \mathrm{m}^{2} /\right.$ day $)$ & & & \\
N.Oc/B.Pm $(1 / \mathrm{mm})$ & $1.8 \pm 0.2$ & $2.3 \pm 0.2$ & 0.105 \\
\hline
\end{tabular}

Table 2

Cortical morphology parameters between saline- and N-AcGIP-treated animals.

\begin{tabular}{llll}
\hline & Saline-treated animals & N-AcGIP-treated animals & p values \\
\hline B.Dm $(\mathrm{mm})$ & $4.26 \pm 0.06$ & $4.32 \pm 0.02$ & 0.400 \\
Ma.Dm $(\mathrm{mm})$ & $3.52 \pm 0.06$ & $3.59 \pm 0.04$ & 0.338 \\
Ct.Th $(\mu \mathrm{m})$ & $369 \pm 12$ & $361 \pm 9$ & 0.585 \\
CSMI $\left(\mathrm{mm}^{4}\right)$ & $8.6 \pm 0.5$ & $8.8 \pm 0.1$ & 0.690 \\
Es.MAR $(\mu \mathrm{m} /$ day $)$ & $2.7 \pm 0.2$ & $3.6 \pm 0.4^{*}$ & 0.028 \\
Es.MS $/$ BS & $0.3 \pm 0.1$ & $0.4 \pm 0.1$ & 0.827 \\
Es.BFR/BS & $0.9 \pm 0.0$ & $1.4 \pm 0.1^{*}$ & 0.026 \\
$\quad\left(\mu \mathrm{m}^{3} / \mu \mathrm{m}^{2} /\right.$ day $)$ & & & \\
N.Oc/Ec.Le $(1 / \mathrm{mm})$ & $0.5 \pm 0.1$ & $0.7 \pm 0.1^{*}$ & 0.026 \\
\hline
\end{tabular}

\footnotetext{
* $\mathrm{p}<0.05$ vs. saline-treated animals.
} 
(A)

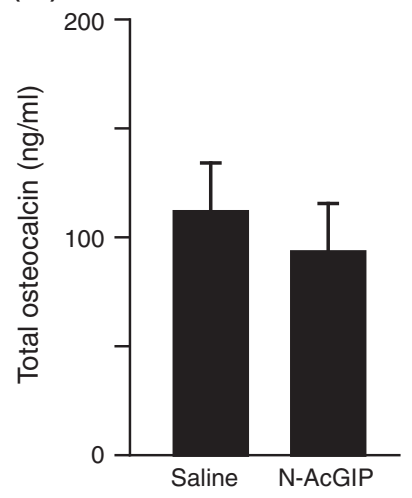

(B)

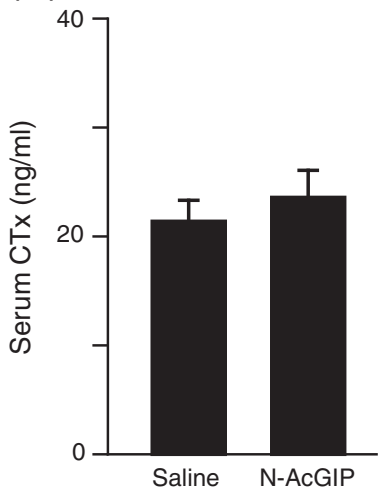

Fig. 3. Serum levels of (A) total osteocalcin and (B) sCTx were not significantly different between saline- and N-AcGIP-treated animals.

modifications of cortical bone microstructural morphology were observed with N-AcGIP treatment. On the other hand, Ct.MAR and N.Oc/Ec.Le were significantly augmented in N-AcGIP-treated animals, but serum markers of bone remodeling (total osteocalcin, CTx) were not statistically different between groups. Taken together, these results suggested that 4 week treatment with N-AcGIP did not alter bone cell activities and microstructural morphology at the endosteal surface, where both osteoblast and osteoclast activities are higher. One reason for this could be related to the dose of GIP analog employed in the study. However, N-AcGIP has already been used in several animal studies, at the same dose employed in the present study ( $25 \mathrm{nmol} / \mathrm{kg}$ body weight/day), and shown to be biologically active [15,23,24].

Another part of our investigation was related to the potential effect of N-AcGIP on bone tissue properties. Indeed, GIPR-deficient animals exhibit reduced bone strength, in part attributed to decreased tissue properties (bone mineralization and collagen maturity) in trabecular and cortical bones $[9,10]$. In the present study, mechanical assessment of the bone matrix at the tissue-level by nanoindentation revealed that N-AcGIP had no effect in trabecular bone. Insignificant augmentations in bone mineralization and collagen maturity were observed in trabecular bone of treated animals, but these modifications are unlikely to substantially improve mechanical properties of the trabecular bone matrix. On the other hand, mechanical properties of cortical bone at the macro- (work to fracture) and tissue-level (maximum load, hardness, indentation modulus and dissipated energy) were significantly improved in N-AcGIP-treated animals as compared with saline controls. These augmentations may be linked to the significantly enhanced bone mineralization and collagen maturity observed by qBEI and FTIR. Taken together, these data suggest that tissue properties are rapidly modified by N-AcGIP and that cortical bone represents the primary target.

We did not look at gene expression in isolated bone cells from treated animals. However, we did investigate the direct effects of N-AcGIP on collagen maturity, AlkP activity and mineralization in the murine MC3T3 cell line. Previously, Bollag et al. reported that GIP stimulates the

Table 3

Mechanical response of the bone tissue at the macro-level.

\begin{tabular}{lccc}
\hline & $\begin{array}{l}\text { Saline- } \\
\text { treated animals }\end{array}$ & $\begin{array}{l}\text { N-AcGIP- } \\
\text { treated animals }\end{array}$ & p values \\
\hline Bending stress (MPa) & $109.2 \pm 5.2$ & $122.1 \pm 7.0$ & 0.117 \\
Bending strain & $0.042 \pm 0.001$ & $0.046 \pm 0.002$ & 0.165 \\
Bending modulus (GPa) & $12.9 \pm 1.2$ & $14.8 \pm 1.3$ & 0.118 \\
$\begin{array}{l}\text { Work-to-fracture } \\
\left(\mathrm{KJ} / \mathrm{m}^{2}\right)\end{array}$ & $4.2 \pm 0.3$ & $5.9 \pm 0.5^{*}$ & 0.025 \\
\hline
\end{tabular}

\footnotetext{
* $\mathrm{p}<0.05$ vs. saline-treated animals.
}

Table 4

Mechanical response of the bone matrix at the tissue-level.

\begin{tabular}{lccc}
\hline & $\begin{array}{l}\text { Saline- } \\
\text { treated animals }\end{array}$ & $\begin{array}{l}\text { N-AcGIP- } \\
\text { treated animals }\end{array}$ & p values \\
\hline Trabecular bone & & & \\
Maximum load (mN) & $12.7 \pm 0.7$ & $12.5 \pm 0.1$ & 0.938 \\
Hardness (MPa) & $714.6 \pm 44.0$ & $694.8 \pm 9.6$ & 0.670 \\
Indentation Modulus (GPa) & $13.7 \pm 0.8$ & $13.4 \pm 0.2$ & 0.810 \\
Dissipated energy (mN nm) & $3592 \pm 143$ & $3577 \pm 134$ & 0.942 \\
& & & \\
Cortical bone & $12.2 \pm 0.4$ & $13.7 \pm 0.2^{* *}$ & 0.009 \\
Maximum load (mN) & $651.3 \pm 18.6$ & $740.9 \pm 26.7^{*}$ & 0.028 \\
Hardness (MPa) & $13.6 \pm 0.2$ & $15.4 \pm 0.5^{*}$ & 0.016 \\
Indentation modulus (GPa) & $3095 \pm 104$ & $3596 \pm 70^{* *}$ & 0.009 \\
Dissipated energy (mN nm) & & & \\
\hline$* \quad \mathrm{p}<0.05$ vs. saline-treated animals. & & \\
$* *$ p $<0.01$ vs. saline-treated animals. & &
\end{tabular}

expression of the col1a gene in osteoblast cultures in vitro [5]. In the present study, we demonstrated that collagen maturity, as determined by FTIR, was higher in N-AcGIP-treated cultures. Furthermore, we clearly show that N-AcGIP was capable of increasing AlkP activity and mineralization directly. Although osteoblast activities are directly modulated by $\mathrm{N}$-AcGIP treatment, we cannot rule out the possible involvement of secondary indirect mechanism in vivo, since the GIPR is expressed in numerous tissues, as well as in bone [37]. For example, the GIPR is expressed in the adrenal cortex of rats and administration of GIP increases corticosterone levels via a cAMP-dependent manner [38]. We did not assess corticosterone levels in our study, although it is unlikely that corticosterone contributed to the observed bone phenotype, as glucocorticoids decrease bone tissue properties [39]. An additional extraosseous locus of GIP action is the endocrine pancreas. In this study, we did not monitor basal insulin levels. However, we previously assessed this parameter in ob/ob diabetic mice treated for 14 days with $\mathrm{N}$-AcGIP. This treatment regimen did not modify plasma insulin as compared with saline controls [23,24]. Nevertheless, we cannot rule out a potential role for insulin in the observed bone phenotype in the current study. Further studies will be required to fully characterize the mechanisms by which N-AcGIP improves bone material properties.

Recently, a study by Ascenzi et al., reported an augmentation in heterogeneity of collagen orientation and mineralization in cortical bone of postmenopausal women treated with parathyroid hormone [40]. In our study, N-AcGIP did modify collagen maturity and mineralization, but we do report a higher collagen maturity and degree of mineralization, with no significant modifications of mineralization heterogeneity. Furthermore, the carbon-to-phosphate ratios were unchanged in trabecular and cortical components, suggesting that the maturity of the mineral was unchanged. However, further investigation of the mineral crystal size would be needed to assess whether this parameter could be altered with N-AcGIP treatment.

In conclusion, 4 week treatment with N-AcGIP improved bone material properties in rats, and especially bone mineralization and

Table 5

Bone mineral density distribution in trabecular and cortical bone.

\begin{tabular}{lrrr}
\hline & Saline-treated animals & N-AcGIP-treated animals & p values \\
\hline Trabecular bone & & & \\
$\mathrm{Ca}_{\text {peak }}(\% \mathrm{Ca})$ & $21.8 \pm 1.0$ & $24.5 \pm 1.0$ & 0.095 \\
$\mathrm{Ca}_{\text {mean }}(\% \mathrm{Ca})$ & $20.2 \pm 0.8$ & $22.2 \pm 0.8$ & 0.125 \\
$\mathrm{Ca}$ width $\% \mathrm{Ca})$ & $6.2 \pm 0.3$ & $6.5 \pm 0.6$ & 0.689 \\
Cortical bone & & & \\
$\mathrm{Ca}$ peak $(\% \mathrm{Ca})$ & $25.5 \pm 0.9$ & $27.9 \pm 0.5^{*}$ & 0.042 \\
$\mathrm{Ca}_{\text {mean }}(\% \mathrm{Ca})$ & $24.5 \pm 0.9$ & $26.8 \pm 0.5^{*}$ & 0.043 \\
$\mathrm{Ca}_{\text {width }}(\% \mathrm{Ca})$ & $4.7 \pm 0.4$ & $4.5 \pm 0.3$ & 0.678 \\
\hline
\end{tabular}

${ }^{*} \mathrm{p}<0.05$ vs. saline-treated animals. 

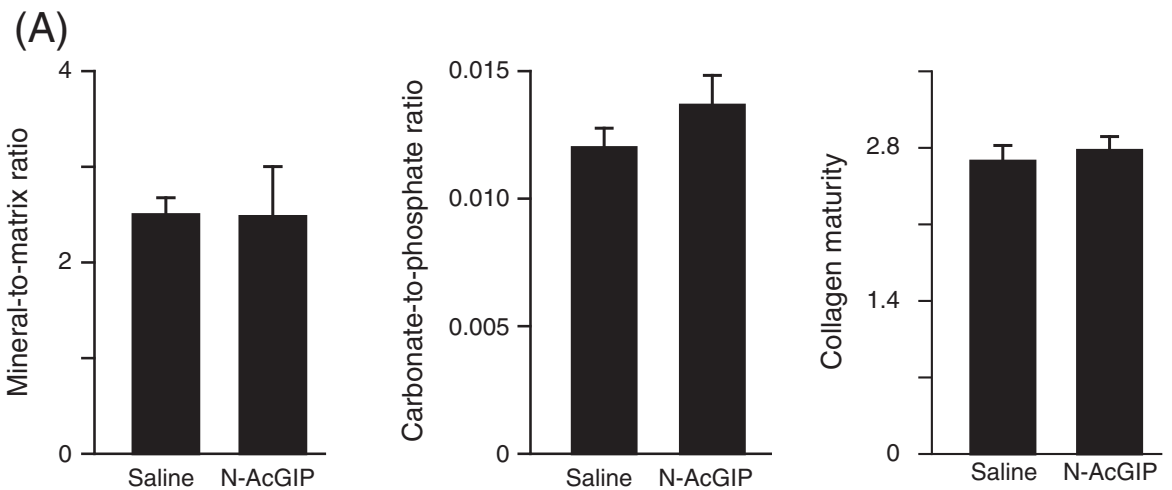

(B)
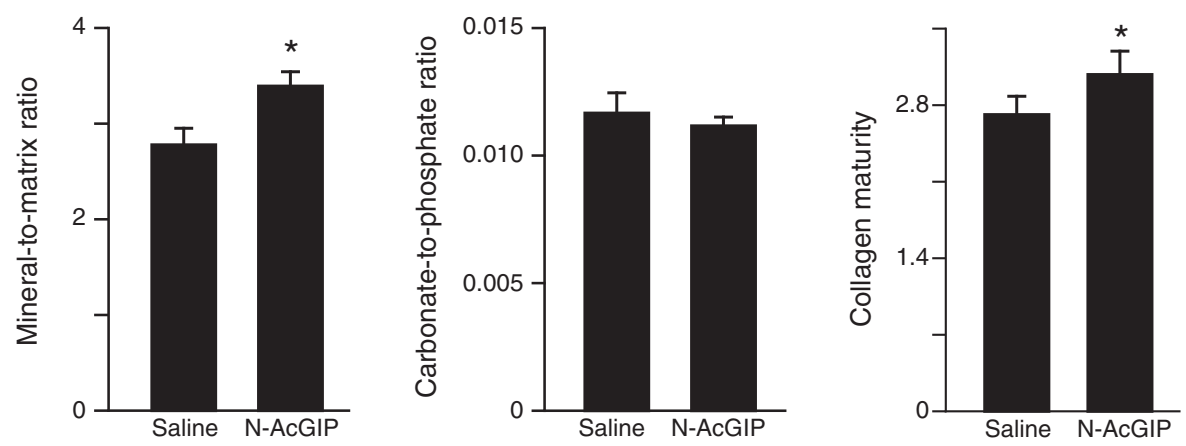

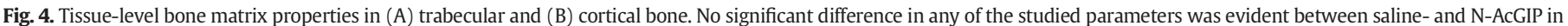
trabecular bone. However, mineral-to-matrix ratio and collagen maturity were significantly higher in cortical bone of N-AcGIP treated rats. ${ }^{*}$ : $\mathrm{p}<0.05$ vs. saline-treated animals.

(A)

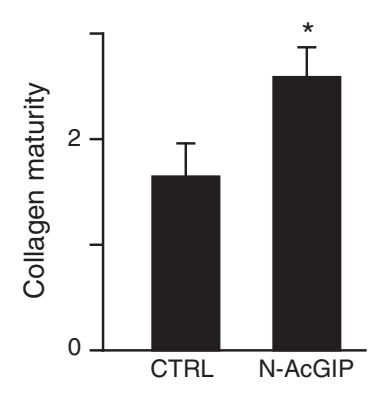

(B)

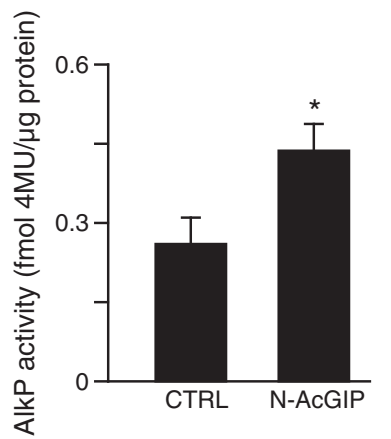

(C)

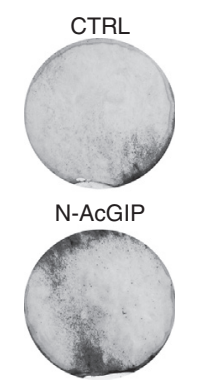

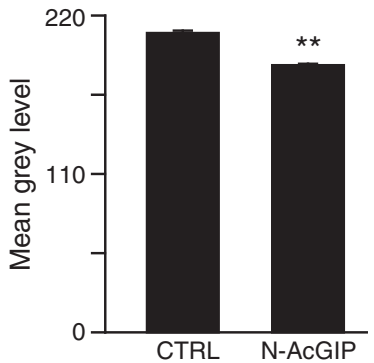

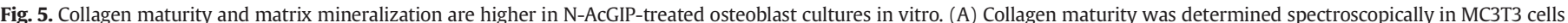

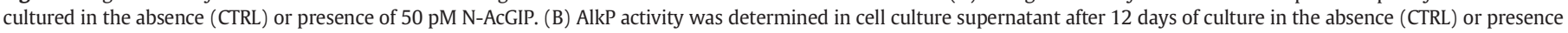

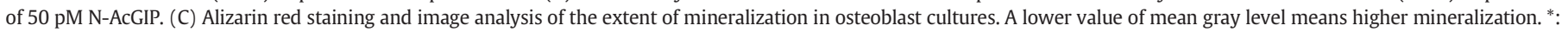
$\mathrm{p}<0.05$ and $^{* *}: \mathrm{p}<0.01$ vs control cultures.

collagen maturity. Although molecular mechanisms leading to such phenotype still need to be clarified, the use of N-AcGIP might represent an alternative exciting treatment option for bone pathologies with decreased material properties, such as osteoporosis.

\section{Acknowledgments}

The authors are grateful to N. Gaborit and G. Brossard for their help with microCT and the team of the Service Commun d'Animalerie Hospitalo-Universitaire (SCAHU) - University of Angers. This work was supported by grants from Contrat Région Pays de la Loire: Bioregos2 program and the University of Ulster Proof of Principle funding program.

\section{References}

[1] Cho YM, Kieffer TJ. K-cells and glucose-dependent insulinotropic polypeptide in health and disease. Vitam Horm 2010;84:111-50.

[2] Wu T, Rayner CK, Jones K, Horowitz M. Dietary effects on incretin hormone secretion. Vitam Horm 2010;84:81-110.

[3] Baggio LL, Drucker DJ. Biology of incretins: GLP-1 and GIP. Gastroenterology 2007;132:2131-57.

[4] Dupre J, Ross SA, Watson D, Brown JC. Stimulation of insulin secretion by gastric inhibitory polypeptide in man. J Clin Endocrinol Metab 1973;37: 826-8.

[5] Bollag RJ, Zhong Q, Phillips P, Min L, Zhong L, Cameron R, et al. Osteoblast-derived cells express functional glucose-dependent insulinotropic peptide receptors. Endocrinology 2000;141:1228-35.

[6] Mabilleau G, Gaudin-Audrain C, Irwin N, Flatt PR, Basle MF, Chappard D. Deficiency in glucose-dependent insulinotropic polypeptide receptor results in higher bone mass in male mice. Osteoporos Int 2012;23:S407-8. 
[7] Zhong Q, Itokawa T, Sridhar S, Ding KH, Xie D, Kang B, et al. Effects of glucosedependent insulinotropic peptide on osteoclast function. Am J Physiol Endocrinol Metab 2007;292:E543-8.

[8] Zhong Q, Ding KH, Mulloy AL, Bollag RJ, Isales CM. Glucose-dependent insulinotropic peptide stimulates proliferation and TGF-beta release from MG-63 cells. Peptides 2003;24:611-6.

[9] Gaudin-Audrain C, Irwin N, Mansur S, Flatt PR, Thorens B, Basle M, et al. Glucose-dependent insulinotropic polypeptide receptor deficiency leads to modifications of trabecular bone volume and quality in mice. Bone 2013;53: 221-30.

[10] Mieczkowska A, Irwin N, Flatt PR, Chappard D, Mabilleau G. Glucose-dependent insulinotropic polypeptide (GIP) receptor deletion leads to reduced bone strength and quality. Bone 2013;56:337-42.

[11] Meier JJ, Nauck MA, Kranz D, Holst JJ, Deacon CF, Gaeckler D, et al. Secretion, degradation, and elimination of glucagon-like peptide 1 and gastric inhibitory polypeptide in patients with chronic renal insufficiency and healthy control subjects. Diabetes 2004;53:654-62.

[12] Deacon CF, Nauck MA, Meier J, Hucking K, Holst JJ. Degradation of endogenous and exogenous gastric inhibitory polypeptide in healthy and in type 2 diabetic subjects as revealed using a new assay for the intact peptide. J Clin Endocrinol Metab 2000; 85:3575-81.

[13] Kieffer TJ, McIntosh CH, Pederson RA. Degradation of glucose-dependent insulinotropic polypeptide and truncated glucagon-like peptide 1 in vitro and in vivo by dipeptidyl peptidase IV. Endocrinology 1995;136:3585-96.

[14] Gault VA, Flatt PR, Bailey CJ, Harriott P, Greer B, Mooney MH, et al. Enhanced cAMP generation and insulin-releasing potency of two novel Tyr1-modified enzymeresistant forms of glucose-dependent insulinotropic polypeptide is associated with significant antihyperglycaemic activity in spontaneous obesity-diabetes. Biochem J 2002;367:913-20.

[15] O'Harte FP, Gault VA, Parker JC, Harriott P, Mooney MH, Bailey CJ, et al. Improved stability, insulin-releasing activity and antidiabetic potential of two novel Nterminal analogues of gastric inhibitory polypeptide: N-acetyl-GIP and pGlu-GIP. Diabetologia 2002;45:1281-91.

[16] O'Harte FP, Mooney MH, Flatt PR. NH2-terminally modified gastric inhibitory polypeptide exhibits amino-peptidase resistance and enhanced antihyperglycemic activity. Diabetes 1999;48:758-65.

[17] O'Harte FP, Mooney MH, Kelly CM, Flatt PR. Improved glycaemic control in obese diabetic ob/ob mice using N-terminally modified gastric inhibitory polypeptide. J Endocrinol 2000;165:639-48.

[18] Varga F, Rumpler M, Zoehrer R, Turecek C, Spitzer S, Thaler R, et al. T3 affects expression of collagen I and collagen cross-linking in bone cell cultures. Biochem Biophys Res Commun 2010;402:180-5.

[19] Mahoney DJ, Mikecz K, Ali T, Mabilleau G, Benayahu D, Plaas A, et al. TSG-6 regulates bone remodeling through inhibition of osteoblastogenesis and osteoclast activation. J Biol Chem 2008;283:25952-62.

[20] Fernley HN, Walker PG. Kinetic behaviour of calf-intestinal alkaline phosphatase with 4-methylumbelliferyl phosphate. Biochem J 1965;97:95-103.

[21] Roberts IM, Jones SL, Premier RR, Cox JC. A comparison of the sensitivity and specificity of enzyme immunoassays and time-resolved fluoroimmunoassay. J Immunol Methods 1991;143:49-56.

[22] Blouin S, Moreau MF, Basle MF, Chappard D. Relations between radiograph texture analysis and microcomputed tomography in two rat models of bone metastases. Cells Tissues Organs 2006;182:182-92.

[23] Irwin N, Clarke GC, Green BD, Greer B, Harriott P, Gault VA, et al. Evaluation of the antidiabetic activity of DPP IV resistant N-terminally modified versus mid-chain acylated analogues of glucose-dependent insulinotropic polypeptide. Biochem Pharmacol 2006;72:719-28.

[24] Irwin N, McClean PL, Flatt PR. Comparison of the subchronic antidiabetic effects of DPP IV-resistant GIP and GLP-1 analogues in obese diabetic (ob/ob) mice. J Pept Sci 2007;13:400-5.

[25] Bouxsein ML, Boyd SK, Christiansen BA, Guldberg RE, Jepsen KJ, Muller R. Guidelines for assessment of bone microstructure in rodents using micro-computed tomography. J Bone Miner Res 2010;25:1468-86.

[26] Dempster DW, Compston JE, Drezner MK, Glorieux FH, Kanis JA, Malluche H, et al. Standardized nomenclature, symbols, and units for bone histomorphometry: a 2012 update of the report of the ASBMR Histomorphometry Nomenclature Committee. J Bone Miner Res 2013;28:2-17.

[27] Chappard D, Alexandre C, Riffat G. Histochemical identification of osteoclasts. Review of current methods and reappraisal of a simple procedure for routine diagnosis on undecalcified human iliac bone biopsies. Basic Appl Histochem 1983;27: 75-85.

[28] Turner CH, Burr DB. Basic biomechanical measurements of bone: a tutorial. Bone 1993;14:595-608.

[29] Ritchie RO, Koester KJ, Ionova S, Yao W, Lane NE, Ager 3rd JW. Measurement of the toughness of bone: a tutorial with special reference to small animal studies. Bone 2008;43:798-812.

[30] Roschger P, Fratzl P, Eschberger J, Klaushofer K. Validation of quantitative backscattered electron imaging for the measurement of mineral density distribution in human bone biopsies. Bone 1998;23:319-26.

[31] Chappard D, Basle MF, Legrand E, Audran M. New laboratory tools in the assessment of bone quality. Osteoporos Int 2011;22:2225-40.

[32] Mabilleau G, Mieczkowska A, Irwin N, Flatt PR, Chappard D. Optimal bone mechanical and material properties require a functional GLP-1 receptor. J Endocrinol 2013;219:59-68.

[33] Oliver WC, Pharr GM. An improved technique for determining hardness and elastic modulus using load and displacement sensing indentation experiments. J Mater Res 1992;7:1564-83.

[34] Paschalis EP, DiCarlo E, Betts F, Sherman P, Mendelsohn R, Boskey AL. FTIR microspectroscopic analysis of human osteonal bone. Calcif Tissue Int 1996;59: 480-7.

[35] Boskey AL, DiCarlo E, Paschalis E, West P, Mendelsohn R. Comparison of minera quality and quantity in iliac crest biopsies from high- and low-turnover osteoporosis: an FT-IR microspectroscopic investigation. Osteoporos Int 2005;16:2031-8.

[36] Paschalis EP, Verdelis K, Doty SB, Boskey AL, Mendelsohn R, Yamauchi M. Spectroscopic characterization of collagen cross-links in bone. J Bone Miner Res 2001;16: 1821-8.

[37] McIntosh CH, Widenmaier S, Kim SJ. Glucose-dependent insulinotropic polypeptide (Gastric Inhibitory Polypeptide; GIP). Vitam Horm 2009;80:409-71.

[38] Mazzocchi G, Rebuffat P, Meneghelli V, Malendowicz LK, Tortorella C, Gottardo G et al. Gastric inhibitory polypeptide stimulates glucocorticoid secretion in rats, acting through specific receptors coupled with the adenylate cyclase-dependent signaling pathway. Peptides 1999;20:589-94.

[39] Lane NE, Yao W, Balooch M, Nalla RK, Balooch G, Habelitz S, et al. Glucocorticoidtreated mice have localized changes in trabecular bone material properties and osteocyte lacunar size that are not observed in placebo-treated or estrogendeficient mice. J Bone Miner Res 2006;21:466-76.

[40] Ascenzi MG, Liao VP, Lee BM, Billi F, Zhou H, Lindsay R, et al. Parathyroid hormone treatment improves the cortical bone microstructure by improving the distribution of type I collagen in postmenopausal women with osteoporosis. J Bone Miner Res 2012;27:702-12. 